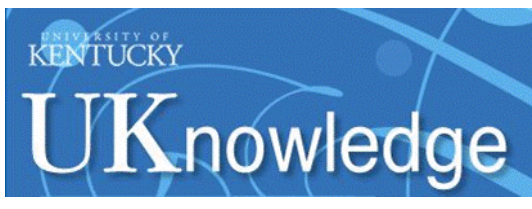

University of Kentucky

UKnowledge

Kentucky Tobacco Research and Development

Center Faculty Publications

Tobacco Research and Development

$10-2016$

\title{
Natural Variability in Acyl Moieties of Sugar Esters Produced by Certain Tobacco and Other Solanaceae Species
}

Antoaneta B. Kroumova

University of Kentucky, amihaylo@uky.edu

David Zaitlin

University of Kentucky, dzait2@uky.edu

George J. Wagner

University of Kentucky, gwagner@uky.edu

Right click to open a feedback form in a new tab to let us know how this document benefits you.

Follow this and additional works at: https://uknowledge.uky.edu/ktrdc_facpub

Part of the Plant Sciences Commons

\section{Repository Citation}

Kroumova, Antoaneta B.; Zaitlin, David; and Wagner, George J., "Natural Variability in Acyl Moieties of Sugar Esters Produced by Certain Tobacco and Other Solanaceae Species" (2016). Kentucky Tobacco Research and Development Center Faculty Publications. 15.

https://uknowledge.uky.edu/ktrdc_facpub/15

This Article is brought to you for free and open access by the Tobacco Research and Development at UKnowledge. It has been accepted for inclusion in Kentucky Tobacco Research and Development Center Faculty Publications by an authorized administrator of UKnowledge. For more information, please contact UKnowledge@lsv.uky.edu. 
Natural Variability in Acyl Moieties of Sugar Esters Produced by Certain Tobacco and Other Solanaceae Species

Notes/Citation Information

Published in Phytochemistry, v. 130, p. 218-227.

(C) 2016 Elsevier Ltd. All rights reserved.

This manuscript version is made available under the CC-BY-NC-ND 4.0 license

http://creativecommons.org/licenses/by-nc-nd/4.0/

Digital Object Identifier (DOI)

https://doi.org/10.1016/j.phytochem.2016.05.008 
(C) 2016 Elsevier Ltd. All rights reserved.

This manuscript version is made available under the CC-BY-NC-ND 4.0 license

http://creativecommons.org/licenses/by-nc-

nd $/ 4.0 /$ 
Natural variability in acyl moieties of sugar esters produced by certain tobacco and other Solanaceae species Antoaneta B.M. Kroumova*, Dave Zaitlin, George J. Wagner

Twenty different acyl groups were identified and quantified in 45 accessions, species, and cultivars. Three unusual acids were found in a few Nicotiana species: octanoate, 8-methyl nonanoate, and decanoate.

(A) General sucrose ester structure for tobacco cultivars, N. obtusifolia, N. alata, and N. noctiflora. Three acyl groups are esterified to carbons 2, 3 and 4 of the glucose moiety. $R$ can be any acyl group with three to eight carbons in length. $R_{1}$ can be $\mathrm{H}$ or acetyl group. (B) The structures of straight, iso- and anteiso- branched carbon chains.

A. General sucrose ester structure

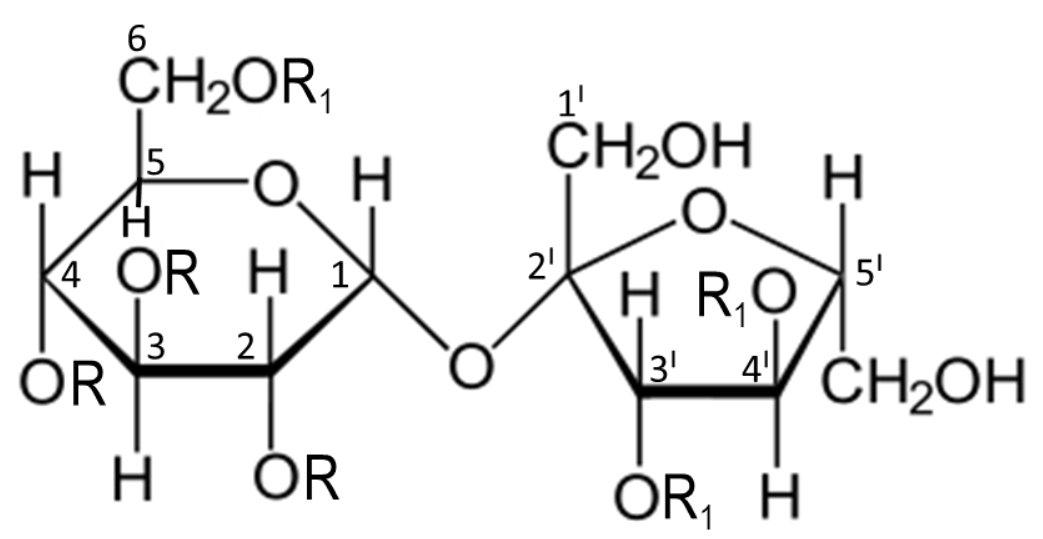

$\mathrm{R}_{1}=\mathrm{H}$ or acetyl group

$\mathrm{R}=$ branched- or straight-chain $\mathrm{C}_{3}-\mathrm{C}_{8}$ acyl groups
B. Examples of carbon chain structure for R:<smiles>CC(C)CC(=O)O</smiles>

iso-chain: 3-methyl butyrate $\left(C_{5}\right)$<smiles>CCC(C)CC(=O)O</smiles>

anteiso-chain: 3-methyl valerate $\left(\mathrm{C}_{6}\right)$<smiles>CCCCCCCC(=O)O</smiles>

straight-chain: octanoate $\left(C_{8}\right)$ 


\section{Highlights:}

- Acyl moieties of Solanaceae sugar esters vary in carbon length and isomer structure.

- Octanoic acid is synthesized by Nicotiana alata and $N$. $\times$ sanderae.

- $\quad$. hesperis is exceptional in producing 8-methyl nonanoate and decanoate.

- Tobacco acyl groups have fewer carbons than those from non-tobacco species.

- Straight-chain acids are rare in sugar esters from Nicotiana species. 


\section{${ }^{\star}$ Revised Manuscript}

\section{Click here to view linked References}

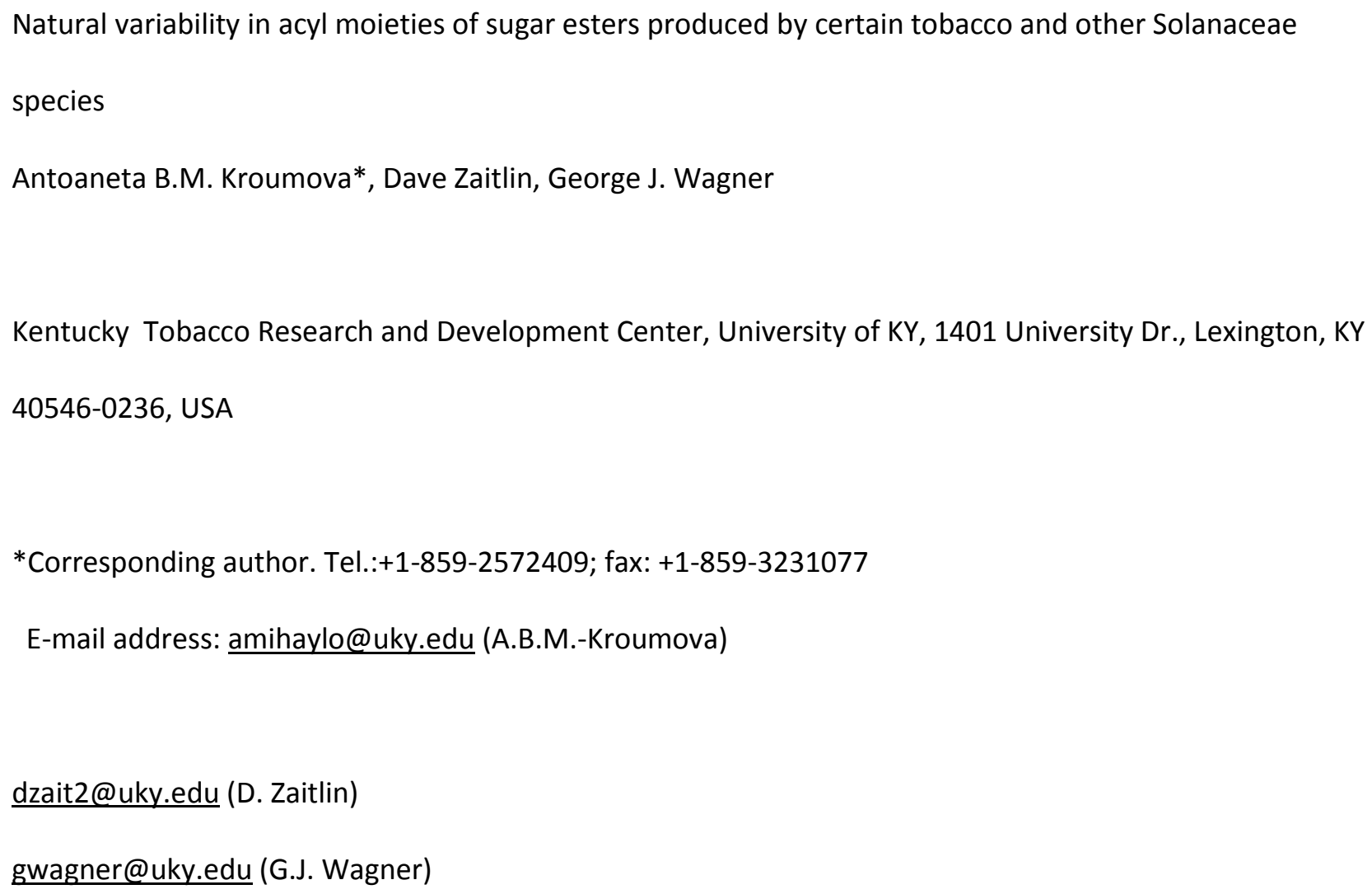




\section{Keywords:}

Nicotiana species

Petunia hybrida

Solanaceae

Glandular trichomes

Natural variability

Sugar esters

Acyl groups 


\section{Introduction:}

Plant trichomes are epidermal protuberances found on the surfaces of many plants. They play an important role in plant defense by providing protection against fungi, insects, herbivores, bacteria, and mechanical damage (Wagner et al., 2004). Trichomes vary in shape, function, and density. Some plants have both glandular and non-glandular types of trichomes, while others have strictly non-glandular ones (Wagner, 1991; Glass et al., 2012; Tissier, 2012). Species in the Solanaceae are well known for the presence of exudates produced by glandular trichomes (GTs) that contribute substantially to the diversity of plant surface chemistry (Wagner, 1999). Trichome exudates from this family can contain terpenoids, phenylpropanoids, flavonoid aglycones, and sugar esters (SEs) that are species- and cultivar-specific (Shepherd and Wagner, 2012). Sugar esters are produced by the GTs of this family. These natural products are non-volatile and are deposited on the leaf surface, comprising as much as $25 \%$ of the trichome exudate in some Nicotiana tabacum (N. tabacum) cultivars (Kelsey et al., 1984). In Solanum pennellii and some tobacco cultivars, they can accumulate to levels up to $20 \%$ and $17 \%$, respectively, of leaf dry weight (Fobes et al., 1985, Wagner et al., 2004). Sugar esters have antiovipositional, antifeedant and toxic properties, and insecticidal and miticidal activity stronger than the insecticidal soap (Chortyk et `al., 1997; Puterka et al., 2003). They also have inhibitory effects on tobacco seed germination and seedling growth (Peterson et al., 1998). Sugar esters have great potential as a new class of pesticides that degrade rapidly and are not known to be harmful to wildlife and other non-target organisms (http://www.csrees.usda.gov/funding/sbir/success/avachem.pdf). SEs also have potential as antibiotics, for cosmetic applications, and as food-grade sucrose esters (Chortyk et al., 1993; Hill and Rhode, 1999). Sugar esters consist of acyl moieties esterified to the hydroxyl groups of sugars (sucrose or glucose). Acyl groups vary in their length (from $\mathrm{C}_{2}$ to $\mathrm{C}_{12}$ ) and backbone structure (iso-branched, anteiso-branched and straight carbon chain) (Severson et al., 1985; Burk et al., 1987). The purpose of this diversity is not clear. The pathway for biosynthesis of SEs is known for several species. In N. benthamiana, N. gossei and N. 
glutinosa, the alpha ketoacid elongation ( $\alpha-\mathrm{KAE}$ ) pathway produces medium-length, branched chain acids. In petunia, this pathway is also involved in the synthesis of straight-chain acids, while in Datura and $S$. pennellii, straight-chain acids appear to come from the fatty acid synthesis (FAS) pathway (Kroumova and Wagner, 2003; Walters and Steffens 1990). The short length, branched-chain groups methyl propionate (MePro)(4), and 2- and 3-methyl butyrate (2-MeBut(6), and 3-MeBut(7)) come from the pathways for synthesis of the essential amino acids valine, iso-leucine and leucine and are products of the first step of their degradations, and MePro(4) is the precursor for 8-methyl nonanoate (8-MeNon) (18) in S. pennellii (Walters and Steffens 1990) (see Fig. 1).

Trichome-produced secondary metabolites in general, and sugar esters in particular, are attractive targets for investigation for the purpose of breeding, engineering of herbivore resistance, resistance against $P$. infestans, pesticide application, and selection for aroma and flavor (Holley et al. 1987; Glas et al. 2012; Leffingwell, 1999). However, more knowledge about the natural production and function of SEs, and the causes of natural variability observed among species and cultivars, needs to be gained.

From what is known about the extent of biodiversity of SE types (chemical diversity and regiospecificity of acyl groups) found in the Solanaceae, it is clear that many individual SE structures containing short- and medium-chain fatty acids are present in these plants. In the genus Nicotiana, structural and/or total acyl identification of sugar esters has been reported for several Nicotiana species and $N$. tabacum varieties (Kaburaki et al., 1969; Kallianos, 1976; Severson et al. 1984, 1985a, 1985b; Arrendale et al., 1990; Matsuzaki et al., 1989, 1992; Ohya et al., 1994; Jia et al., 2013). The purpose of the study was to analyze acyl group composition and acyl abundance diversity among some species in the genus Nicotiana and among some cultivars of N. tabacum. For accuracy, the abundance of acyl groups was expressed in molarity. Variability was found among species, cultivars, accessions, and even 
between different organs (leaves vs stems) of the same species. This appears to be another level of variability in addition to the structural diversity.

Herein described is the analysis of total sugar ester acyl composition in 21 accessions of $N$. obtusifolia, six of N. occidentalis subsp. hesperis, two of N. occidentalis, three each of N. alata, N. $\times$ sanderae, and $N$.

noctiflora, four cultivars of modern tobacco, five petunia hybrids, and single accessions of the wild potato $S$. berthaultii and the wild tomato S. pennellii.

\section{Results}

2.1. Calculation of molarity of acyl groups on the basis of the peak areas

GC chromatograms obtained for butyl esters of SE acyl groups from Nicotiana species of interest contain numerous peaks, reflecting the diversity of the acyl groups synthesized. The peak areas were measured to assess the abundance of different compounds. In earlier publications related to acyl sugar composition, the authors sometimes postulated that the GC response of all compounds is the same (Chortyk et al., 1997, Peterson, 1998, and Kim et al., 2012). However, from previous liquid chromatography results it is known that there is a difference between responses, depending on chain length and degree of unsaturation (Kroumova and Wagner, 1995). Free acid GC response was also reported not to be representative of component levels (Severson et al., 1985).

In the current study, separation and identification of 8-12 acyl groups (as their butyl esters) per chromatogram was attained, and there abundances in moles were determined using linear regression curves created with standard acids. Each peak from the chromatogram, created with standard acids, was plotted as peak area versus moles of acid (Fig. S1). Each point on the graph was an average of five independent runs using five separate standard solutions. For each acyl butyl ester, a simple linear 
regression curve best fit the relationships of peak area to the molarity. The correlations were very strong, showing $R^{2}>0.995$ for all linear equations (Fig. S1).

As shown in Fig. S1, the absolute slope values of the lines vary greatly which means that when the molarity is equal, higher slope will give higher peak area or higher response, and vice versa. The least responsive was acetate $(\mathrm{Ac})(\mathbf{1})($ slope=1.5256), and the most responsive was laurate (Laur) (20) (slope = 19.666). On the basis of these very different responses, it was not possible to compare Ac (1) and Laur (20) or, for example 5- and 6- methyl heptanoate (5-MeHept (15) and 6-MeHept (16)) and MePro (4). If area \% (\% of the highest) of the compounds in a chromatogram is calculated as a peak area, the wrong major peak could be assigned. This is especially true for Ac (1), as it shows modest peak abundance but very often happens to be a prominent product or the most abundant one. The only two acyl butyrates with very similar responses were 2-MeBut (6) and 5-methyl hexanoate (5-MeHex) (13). The results here are thus in agreement with earlier publications, where slopes of the calibration curves of free or butylated fatty acids having one to eight carbons were proportional to the carbon length (Severson et al., 1985a, Tangreman and Nagengast, 1996, Zhao et al., 2006, and Salanitro and Muirhead, 1975). For $C_{2}$ to $C_{5}$ short chain fatty acids, the GC-MS data are supported by the paper of van Eijk et al. (2009), who used LC-MS to analyze free short chain fatty acids in blood samples.

Linear regression equations were used to convert the peak areas into moles and to then calculate the relative abundance of acyl groups in individual plants. The highest molarity was taken as $100 \%$ and the rest of the acids were expressed as a relative percentage of this.

\subsection{Desert tobaccos from North America}

Desert tobacco N. obtusifolia (formerly known as N. trigonophylla and N. palmerii), is native to arid regions of the southwestern United States (California, Arizona, New Mexico, and Texas) and northern 

ester per 50 plants) that are active against aphids and whiteflies (Jackson et al., 1998). This species can supply sugar esters for use as a biorational insecticide (relatively non-toxic to people and with few environmental side-effects) (Jackson et al., 1998). Sucrose esters of $N$. obtusifolia are predominant over glucose esters (Matsuzaki et al., 1989).

Acyl group analysis was done on the leaves of 21 accessions, in order to find the extent of variability or predictability among these accessions. Of particular interest were acyl groups, as they are very different from those synthesized by commercial tobacco cultivars, i.e. in order to eventually study the enzymes leading to this diversity. As seen from the data in Table 1, the acyl groups in all accessions consisted of Ac (1), MePro (4), But (5), 2-MeBut (6), 3-MeBut (7), 3- and 4 methyl valerate (3-MeVal (9) and 4-MeVal (10)), 4-methyl hexanoate (4-MeHex) (12), 5-MeHex (13), and 5-MeHept (15).

The abundance of all these groups varied among the accessions, with the most variable being 5-MeHept (15) (from $0.5 \%$ of 2-MeBut (6) in ZS05-04, to $100 \%$ in DZO2-014, DZO2-019 and ZH04-8). High variability was observed with respect to the major acyl groups. Ac (1) was the most abundant in three accessions and 2-MeBut (6) - in five accessions. 4-MeHex (12) was the most abundant in all BBNP accessions and in accession 555573. 5-MeHex (13) was the major compound in four accessions, and 5-MeHept (15) - in three accessions.

Considering the total acyl composition of the individual accessions, the anteiso-groups (2-MeBut 6, 3-meVa 9, 4-MeHex 12, and 5-MeHept 15) were prevalent. In ZH04-8 and 555573, these comprise $80.5 \%$ and $80.2 \%$, respectively, of the total anteiso- and iso-groups. A strong presence of the medium length, branched-chain acids 4- and 5-MeHex (12) and (13), and 5-MeHept (15) was very characteristic for all the N. obtusifolia accessions. In all accessions, 6-MeHept (16) was either absent, or when present did not exceed $15 \%$ (15\% of acetate (1) in DZ02-22), and hexanoate (Hex) (11) was detected in minute amounts in five accessions. 


\subsection{Tobacco cultivars, ornamental varieties and wild species}

Four cultivars of N. tabacum L: Tobacco introduction 1068 (TI 1068), line KDH 960; burley cultivars Kentucky 14 (KY14) and TI 165; ornamental species N. alata, the ornamental hybrid $N . \times$ sanderae $(N$. alata $\times$ N. forgetiana), were analyzed, together with the wild species N. sylvestris, and N. noctiflora. TI 1068 is a pale-yellow-type tobacco that synthesizes the highest amount of SE compared to the other cultivars studied, and has been estimated to accumulate $56.6 \mu \mathrm{g} \mathrm{cm}^{-2}$ sugar esters (Nielsen, 1989). Tl 1068 has a high density of secreting GTs $-54.5 / \mathrm{mm}^{2}$ versus, for example, $23 / \mathrm{mm}^{2}$ in $\mathrm{KY} 14$, (Johnson et al 1988). The germplasm line $\mathrm{KDH}-960$ was created as a source of genetic variation for use in studies of trichome exudates and as a biosynthetic source for $\alpha$ - and ß-cembratriene-diols ( $\alpha$ - and B-CBT-diols) (Nielsen, 1989). KY14 is an old commercial burley tobacco cultivar in which sugar esters reach $2 \mathrm{mg} / \mathrm{g}$ tissue at full maturity (Leffingwell, 1999). TI 165 is an accession from Japan known as 'Hatano' and is classified as a cigar filler type (Chaplin et al., 1982). TI 165 was previously reported to yield $9.9 \mu \mathrm{g} / \mathrm{cm}^{2}$ SE (Johnson, 1984). N. sylvestris is considered to be the maternal donor of $N$. tabacum, an allotetraploid species which was formed $\sim 200,000$ years ago by interspecific hybridization with $N$. tomentosiformis (Leitch et al., 1998). N. alata is a species with low drought tolerance and with large white, fragrant flowers, which is native in southern Brazil to northeastern Argentina.

Diversity in acyl composition was observed between the tobacco cultivars. Ac (1) was a major acid in KY14 and KDH960, while 3-MeVal (9) was a predominant acyl group in TI 1068 and TI 165. Carbon chain length also varied. The longest acids were 4-MeVal (10) in TI 1068, octanoate (Oct 17) in KY 14, 5-MeHex (13) in TI 165, and 3-MeBut (7) in KDH 960.

KDH 960 has the smallest variety of acyl groups- only Ac (1) (100\%), 3-MeBut (7) (66\%), 2-MeBut (6) (39\%), MePro (4) (32\%), and But (5) (19\%) (of Ac 1, respectively). KDH 960 has at least 2-3 times fewer acyl groups than does TI 1068 (not shown). This cultivar was derived from parental lines TI 1068 and TI 1406 
(Nielsen, 1989). The reduced amount of SEs compared to TI 1068 could be due to that fact that the TI 1406 parent lacks secreting GTs (Johnson et al., 1988).

The abundance of acyl groups in KY14 was found to be lower than in TI 1068. Exudate was collected from $40 \mathrm{~cm}^{2}$ (vs $6.12 \mathrm{~cm}^{2}$ for T.I. 1068) in order to be able to have enough material for reliable identification of GC peaks. In KY14, Ac (1) is the most abundant group, followed by 2-MeBut (6), 3-MeBut (7), MePro (4), But (5), 4-MeHex (12), 5-MeHex (13) and Oct (17) (Table 2). Among the tobacco cultivars, Oct (17) was observed only in KY14.

The major acyl groups found in TI 165-3-MeVal (9), Ac (1), 3-MeBut (7), and 2-MeBut (6), were identified earlier (Severson et al., 1985a). In current work, however, the minor acids 4-MeVal (10) and 5-MeHex (13) were present, while Val (8), Hex (11), Hept (14) and MeHept (15 and 16) were absent, in contrast to Severson et al (1985a). No Val (8) or Hept (14) was found in any of the tobacco cultivars studied.

Sugar esters are in very low abundance in N. sylvestris, and they were not identified previously in this species (Matsuzaki et al., 1989). Exudate was thus collected from $1,225 \mathrm{~cm}^{2}$ of leaf material and it was possible to recover five acyl groups which were in the order of abundance: Ac (1), 4-MeHex (12), But (5), 5MeHex (13) 2-MeBut (6), 3-MeVal (9) 3-MeBut (7), and 4-MeVal (10). The acyl moieties of SEs in N. sylvestris are reported here for the first time. Due to the minuscule amounts of SEs recovered from $N$. sylvestris, it can be assumed that the SEs in N. tabacum did not originate from this parent, but rather came from N. tomentosiformis (Matsuzaki, 1989).

N. alata produces a mix of glucose and sucrose esters (Matsuzaki et al., 1989). Comparison of the acyl groups from three accessions of this species was carried out, as these accessions have unique compositions consisting of Ac (1), 2-MeBut (6), Oct (17), 3-MeBut (7), MePro (4), But (5), 3-MeVal (9), and Hex (11). Oct (17) and Hex (11) were not previously reported for N. alata (Severson et al., 1991). N. alata PI555474 has lower abundance of Pro (2), 2-MeBut (6), and 3-MeVal (9), and higher abundance of MePro (4), Hex (11) and Oct (17) comparatively to the other two accessions. 

of acids found in $N . \times$ sanderae is similar to that in N. alata (Table 2). The most abundant acyl groups are Oct (17)(100\%), 2-MeBut (6)(87\% of 17), and Ac (1) (62\% of 17).

In N. noctiflora, the major acyl groups are 5-MeHex (13)(100\%), followed by 3-MeBut (7) and Ac (1) (65 and $35 \%$ of $5-\mathrm{MeHex}(\mathbf{1 3})$, respectively). The unique feature of the acyl composition is the predominance of iso-branched-chain groups ( $84 \%$ iso-groups vs. $16 \%$ anteiso groups of the total branched-chain groups) 2.4. Native Nicotiana species from Australia

N. occidentalis subsp. hesperis is a species native to coastal Western Australia and offshore islands (Chase et al., 2003). It produces mainly glucose esters and traces of sucrose esters in the leaves (Matsuzaki et al., 1989). Six accessions were analyzed (Table 3). Leave trichomes did not produce abundant exudate and material was collected from large leaf areas $\left(426 \mathrm{~cm}^{2}\right)$ to examine acyl groups (in contrast, exudate from $6.1 \mathrm{~cm}^{2}$ of TI 1068 was sufficient for reliable peak identification analysis). In addition to leaf SE composition stems and sepals were examined, as they possess abundant exudate-secreting trichomes. However, great variability was observed in acyl abundance among accessions and less variability between organs of the same accession (Table 3). Ac (1) was the major acid in stems of accessions 303765, 303763 and 303764 , and in the leaves of accessions 303765 and 303764, whereby 3-MeVal (9) was the major group detected in 303663, 303767, and 303721, while MePro (4) was major group isolated from leaves of 303763 . The abundance of 3-MeVal (9) varied among accessions from 6.4\% (of Ac 1 in stems of 303765) to 100\% in 303663, 303767 and 303721, and 4-MeVal (10) varied from 5\% (of 3-MeVal 9) in 303767 to 75\% (of Ac 1) in leaves of 303765 and stems of 303763. In accession 303721, 5-MeHex (13) was 77\% in leaves and 3\% in stems (of 3-MeVal 9). Very surprisingly, in four of the accessions (303663, 303763, 303765, and 303764) synthesis of 8-MeNon (18) and decanoate (Dec 19) was detected. To our knowledge, these have not been previously reported to occur in the genus Nicotiana. Dramatic changes were found in the abundance of these two acids during the growth and development of accession PI 303663: in 48 d-old plants, 8meNon 
(18) was the major peak, and Dec (19) was abundant (not shown), while in 80d-old plants 8meNon (18) accounted for $10 \%$ of 3-MeVal (9), and Dec (19) was present in trace amounts (Table 3). Stem SEs from the same accession had only trace amounts of both acids. The composition of all accessions was a mix of isoand anteiso-branched chain acids, but the iso-branched acids prevailed in 303765 and 303763 , while anteiso-branched prevailed in 303663, 303767, and 303764.

N. occidentalis is a short-lived, annual herb native to Australia. Sugar esters are represented only by sucrose esters (Matsuzaki et al., 1989). Accession PI 555541 showed a very similar acyl group profile in leaves and stems, and produced mainly 2-MeBut (6)(100\%), Ac (1) (81\%) and 3-MeVal (9) (63\%) (of 2MeBut 6). No carbon chain $>6$ carbons was detected. Accession PI 555689, in contrast, produces 7- and 8carbon chains, and variable amounts of acyl groups in the leaves, stems, and sepals. Ac (1) was the predominant acyl group in all organs. 3-MeVal (9) was 66\% (of Ac 1) in the leaves, but was not found in sepals. 5-MeHex (13) was $10 \%$ in leaves and 76\% (of Ac $\mathbf{1}$ ) in sepals. The major acids in leaves were Ac (1) and 3-MeVal (9), in stems - Ac (1) and 5-MeHept (15), and in sepals - Ac (1), 5-MeHex (13), and 5-MeHept (15).

2.5. Petunia, S. berthaultii, and S. pennellii.

Trichome glands in petunia produce a complex mixture of glucose and sucrose esters, and the concentrations are known to vary among cultivars (Kays et al., 1994). Petunias SEs were shown to control white fly infestation (Kays et al., 1994). Comparison of the five petunia hybrids analyzed here with data from several cultivars reported in the literature (Son et al., 1994; Kays et al., 1994) resulted in great variability being observed among the hybrids regarding abundance and occurrence of fatty acids (Table 4). Malonate (3) predominated (100\%) in the hybrid cultivars 'Madness Red Picotee', 'Purple Tidal Wave' and 'Pink Tidal Wave' and was second in abundance in 'Dreams Red Picotee' (99\% of 2-MeBut 6) and 'Purple Tidal Wave' (83\% of Hex 11). 2-MeBut (6) was the major group in 'Dreams Red Picotee'. Hex (11) was the dominant group in 'Silver Tidal Wave'. 4-MeHex (12) was present only in 'Pink' and 'Purple Tidal Wave' 


\section{Discussion}

A total of 20 acyl moieties were found in the sugar esters isolated from the different species, cultivars, accessions, and hybrids of Nicotiana, Petunia, and Solanum. In all N. obtusifolia accessions, the strong 
presence of 4- and 5-MeHex (12) and (13), and 5-MeHept (15) was very characteristic. 5-MeHex (12) was also abundant in N. noctiflora (Table 2) (Cutler et al., 1992). These medium length branched-chain groups were found in lesser amounts in N. occidentalis, $N$. occidentalis subsp. hesperis (Table 3 ), and in several other Nicotiana species (Severson et al, 1991, Ohia et al., 1994, Kroumova et al., 1993, Kroumova and Wagner, 2003, and Slocombe et al., 2008). Most of the species studied here have both iso-and anteiso branched carbon chains. However, N. noctiflora synthesizes mainly iso-branched-chain groups (Table 2), while N. obtusifolia accessions ZH04-8 and PI\# 555573 have predominantly anteiso groups (Table 1). The anteiso- branched-chain acids 3-MeVal (9), 4-MeHex (12), and 5-MeHept (15) are the elongation products of 2-oxo-3-MeVal, while the iso-branched-chain acids 4-MeVal (10), 5-MeHex (13), and 6-MeHept (15) are elongation products of 2-oxo-4-MeVal. 2-oxo-3-MeVal and 2-oxo-4-MeVal are the intermediates for synthesis of Leu and Ile.

The acyl group composition of the SEs from KDH960 is unusual compared to the other studied species here because the carbon chains have no more than five carbons. Similarly, only short-chain groups were detected in some accessions of the wild tomato relative S. habrochaites. These accessions were found to lack specific acylsugar acyltransferases (ASAT3-like) that can add long acyl chains to the glucose moiety of SEs (Schilmiller et al., 2015).

The presence of Oct (17) in high levels, and of Hex (11), in leaves of N. alata and N. $x$ sanderae was observed here for the first time. Severson et al. (1991) found only short-chain acids $\left(\leq C_{5}\right)$ in $N$. alata. Straight-chain acids were reported to be minor components in tobacco (Kaburaki et al., 1969 and Kallianos, 1976). Straight-chain acyl groups are rare in the genus Nicotiana. However, they have been found in other Solanaceae species such as Petunia, tomato, wild potato, and Datura. Petunia SEs are distinctive in having numerous straight-chain acids with two to eight carbons $(\mathbf{2}, \mathbf{5}, \mathbf{8}, \mathbf{1 1}, \mathbf{1 4}$, and $\mathbf{1 7})$ including malonate (3), while wild potato and tomato species have longer straight-chain acids (Dec 19 and Laur 20) (Table 4). In Petunia, these acyl groups are synthesized via the $\alpha$-KAE pathway, while in S. pennellii and Datura metel, 
the FAS pathway is involved (Walter and Steffens, 1990, and Kroumova and Wagner, 2003). The origin of the straight-chain acids But (5), Hex (11), and Oct (17) in N. hesperis, N. allata, and N. $\times$ sanderae has not been studied, but either the $\alpha-$ KAE (as in petunia) or FAS pathway (as in Datura or S. pennellii) are possibilities.

N. occidentalis subsp. hesperis accessions are unique in producing 8-MeNon (18) and Dec (19) (Table 3). This is the first report of their occurrence in any species in the genus Nicotiana. In S. pennellii, these groups are produced via FAS, which suggests the same possibility for $N$. occidentalis subsp. hesperis.

In our study, malonate (3) was found to be a major acid in several petunia hybrid cultivars. Earlier publications have shown the presence of malonate, but not in abundance (Ohya et a.l, 1996, and Chortyk et al., 1997). The peak abundance of malonate (3) in the GC chromatograms was not prominent, but due to the low malonate (3) response factor (as expected for three carbons) it is reflected in high nmol abundance. Why malonate (3) is found only in petunia SEs is unclear at present. Petunia species synthesize a lot of anthocyanins, which requires malonyl-CoA (Winkel-Shirley, 2001). A fraction of the activated malonate (malonyl-CoA) can be redirected to form esters with sugars.

There are several important questions that relate to the natural diversity: (1) why do some species synthesize only branched- or straight-chain acids, or both; (2) why in some species do iso-or anteiso- chains prevail; (3) why in tobacco are the acyl chain lengths reduced compared to other Nicotiana species; and (4) why does the desert tobacco ( $N$. obtusifolia) synthesize seven- and eight-carbon branched-chain acids in abundance? To answer these questions, an exploration of the basis of phenotypic diversity and adaptation to natural and agricultural environments is required. Given the complexity of the acyl groups found in this study, much more may be learned about the possibilities for manipulating them so as to use SEs as biorationals to provide increased insect and bacterial resistance. Natural or modified sucrose esters may also prove useful as natural products in the food industry. 


\section{Concluding Remarks}

Significant variability in carbon chain length and branching was observed among sugar ester acyl groups in the Solanaceae species examined in this study, despite the fact that the longest chain length found was 12 carbons. The precise quantification of individual groups, using GC/MS and standard calibration curves, showed also variation in acyl abundance. Similar diversity among major acyl groups has been reported previously in other Nicotiana species (Severson et al., 1991; Chortyk et al., 1993). The major acyl groups in non-tobacco species can be short or medium-chain, while in tobacco they are only short-chain, with a prevalence of 3-MeVal (9) or 2- and 3-MeBut (6 and 7). The pathway for acyl group synthesis was confirmed earlier for several Nicotiana and other species in the Solanaceae (Kroumova and Wagner, 2003; Walters and Steffens 1990), but pathway(s) for straight-chain (11, 17, and 19) synthesis in N. alata, N. sanderae, N. occidentalis subsp. hesperis, and 8-MeNon (18) synthesis in N. occidentalis subsp. hesperis remain to be determined. Revealing the factors underlying interspecies diversity in sugar ester acyl groups will contribute to our ability to improve some plant properties related to defense against abiotic and biotic stress, and to improve the synthetic capacity for industrial applications.

\section{Experimental}

\subsection{General experimental procedure}

\subsubsection{Preparation of standard curves of butyl esters}

The thirteen most-often observed acids in tobacco sugar esters were selected to make standard curves of peak area response to the molarity of the acid. Acetic acid (1) was from Thermo Fisher Scientific Inc.; MePro (4), But (5), 2- and 3-MeBut (6) and (7), Val (8), 3-MeVal (9) and Oct (17) were obtained from SigmaAldrich Co. LLC.; 4- and 5-MeHex (13), 5-and 6-MeHept (15) and (16) were from Narchem ${ }^{\mathrm{TM}}$ Corporation, USA, and 8-MeNon (18) was from Chemica Alta LTD, Canada. The standards were converted to butyl esters in order to increase detection sensitivity by gas chromatography. To determine the retention time and mass spectrum of individual butyl esters on the chromatogram, they were prepared separately. An equal 
volume $(2 \mu \mathrm{L})$ of each standard acid was added to of $1 \mathrm{M} \mathrm{KOH}(500 \mu \mathrm{L})$ in $\mathrm{MeOH}: \mathrm{H}_{2} \mathrm{O}(80: 20, \mathrm{v} / \mathrm{v})$ (to mimic the SE saponification method, see below) and allowed to stand overnight. Samples were dried under a $\mathrm{N}_{2}$ stream at $40^{\circ} \mathrm{C}$; each residue was then dissolved in $n-\mathrm{BuOH}(0.5 \mathrm{~mL})$ containing 3 drops of conc. $\mathrm{H}_{2} \mathrm{SO}_{4}$ and the mixture was heated at $110^{\circ} \mathrm{C}$ for 1 hour. The level of meniscus of the reaction mix was monitored before and after the reaction to ensure no change in volume. After cooling, hexane $(2 \mathrm{~mL})$ was added to the reaction mix and the organic phase was partitioned with $\mathrm{H}_{2} \mathrm{O}$ until the $\mathrm{H}_{2} \mathrm{O}$ reached a pH of 7.0 by litmus paper (modified method of Severson et al., 1985). The hexane phase, containing the butyl esters, was adjusted to $1 \mathrm{~mL}$ and an aliquot injected into the GC. To make calibration curves for the butyl esters, a mixture of 19 authentic standard acids ( $2 \mu \mathrm{L}$ each) was derivatized as above followed by preparation of six dilution stocks. The procedure was repeated four times to create four additional stocks. The standard curve for malonate (3) was prepared separately to monitor for its degradation to Ac (1) during the derivatization. GC/MS chromatograms showed no evidence for malonate (3) degradation. The butyl esters were separated and analyzed by GC-MS (HP6890 GC equipped with HP5973 MS and automatic sampler injector), using a $30.0 \mathrm{~m}$ Agilent capillary column (19091J-413) with $0.25 \mu \mathrm{m}$ film thickness and $0.25 \mathrm{~mm}$ diameter. The GC-MS approach was applied in order to resolve iso- and anteiso- isomers of branched acyl chains. He was used as carrier gas at $1.8 \mathrm{~mL} / \mathrm{min}$ constant flow compensation, and the injection temperature was $250^{\circ} \mathrm{C}$. The oven program for running the butyl ester derivatives was as follows: initial temperature $90^{\circ} \mathrm{C}$ for $3.0 \mathrm{~min}$; rate $-3^{\circ} \mathrm{C} / \mathrm{min}$ until $160^{\circ} \mathrm{C}$, hold $2.0 \mathrm{~min}$; rate $-15^{\circ} \mathrm{C} / \mathrm{min}$ until $250^{\circ} \mathrm{C}$ with a hold for $5.0 \mathrm{~min}$. Total run time was $39.33 \mathrm{~min}$. The butyl esters on the chromatogram were identified according to their retention times and MS profile.

\subsubsection{Preparation of butyl ester derivatives of SE acyl groups and GC-MS analysis}

Collection of leaf exudates was performed essentially as described by Severson et al. (1985). Abundance of SEs varied greatly among species. For plants with abundant sugar esters, two leaf discs $\left(=6.12 \mathrm{~cm}^{2}\right)$ were washed for 1 min with $\mathrm{CH}_{3} \mathrm{CN}$, with these washes vacuum-evaporated to dryness, dissolved in $\mathrm{CHCl}_{3}(1 \mathrm{~mL})$, 
transferred to $1.5 \mathrm{~mL} \mathrm{GC}$ vials and dried. Where SEs were scarce (e.g. N. sylvestris), in order to a obtain sufficient amount for analysis, whole leaves were washed with $\mathrm{CH}_{3} \mathrm{CN}$ for $1 \mathrm{~min}$, then traced on uniform paper, and the image was cut out and weighed to determine the leaf area in $\mathrm{cm}^{2}$. $\mathrm{The}^{\mathrm{CH}} \mathrm{CN}_{3}$ washes were vacuum-evaporated to dryness and dissolved in $\mathrm{CHCl}_{3}(10 \mathrm{~mL})$. Polar impurities were removed by double partitioning with $\mathrm{H}_{2} \mathrm{O} . \mathrm{CHCl}_{3}$ fractions were evaporated to dryness in $\mathrm{GC}$ vials $(1.5 \mathrm{~mL})$. Further saponification, derivatization, GC-MS analysis and acyl identification were done as described in 3.1.1.

\subsection{Plant seed sources, germination, and plant growth}

Seeds of the desert tobacco, N. obtusifolia accessions DZO2-12 to -22, ZH04-08, ZS05-04, and ZS05-05 were collected by D. Zaitlin. Accessions DZ02-12 to -22 were from southern Arizona; ZH04-08 was from Starr County, TX; ZS05-04 was from the Anza-Borrego Desert State Park, San Diego County, CA; ZS05-05 was collected along highway S2, just west of the Anza-Borrego Desert State Park. BBNP-8 to -12 are collections from Big Bend National Park in West Texas, and were the gift of Mr. Joe Sirotnak, BBNP botanist, in 2002. Accessions PI\# 555543 and PI\# 555573 were originally obtained from the USDA Tobacco Collection, and reportedly originated from Arizona and Mexico, respectively (Heist et al. 2004).

N. tabacum varieties TI 1068, TI 165, KY14, and accessions of $N$. sylvestris, and N. noctiflora were obtained from the KTRDC seed collection. N. alata accessions TW 7 (PI\# 42334), TW 8 (PI\# 555474), and TW 9 (PI\# 555473) were originally received from the Germplasm Resources Information Network (GRIN) and are maintained in the KTRDC seed collection. $N . \times$ sanderae accessions were purchased from Plant World Seeds (www.plant-world-seeds.com). N. occidentalis subsp. hesperis accessions AusTRCF 303663, 303763, 303721, 303765, 303767, and 303764 were obtained from the Australian Tropical Crops and Forages Germplasm Centre, Queensland, Australia. N. occidentalis TW 91 accessions PI\#555541 and PI\#555689 were of Australian origin, but were received from GRIN. 


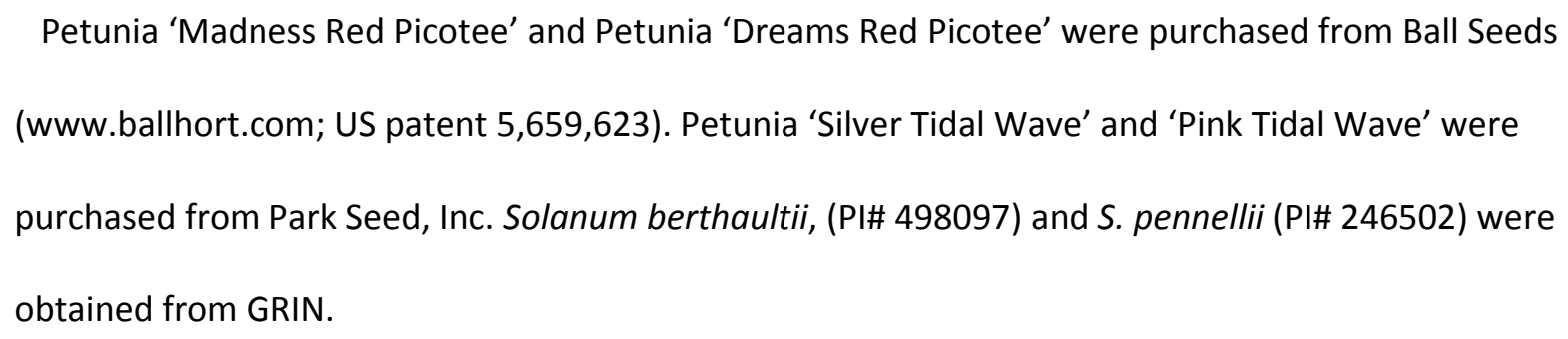

For all species and accessions, seeds were sown on Pro-mix medium (Premier Horticulture Inc., Canada) in 6-inch pots and covered with plastic until germination occurred in a growth chamber at $22.8^{\circ} \mathrm{C}$ with a $16 / 8 \mathrm{~h}$ light/dark regime and $23 \%$ relative humidity. After germination, the plastic was removed and plants were allowed to grow under the same conditions. The seeds of $N$. hesperis, with the exception of PI\# 303663, failed to germinate on soil, so they were sterilized with $\mathrm{EtOH}$ for $1 \mathrm{~min}$, followed by $20 \% \mathrm{NaOCl}$ for $15 \mathrm{~min}$, and grown on MS medium (Murashige and Skoog, 1962) in petri dishes. About ten days later, the seed testa was scratched with a sterile needle under microscope and returned to in vitro conditions to allow moisture and nutrition penetration. One month later seedlings were transferred to soil in pots and grown under fluorescent lighting.

\section{Acknowledgments}

We thank the Kentucky Tobacco Research and Development Center (University of Kentucky), Lexington, KY, USA, for the financial support of this work. We are grateful to James T. Hall (KTRDC, University of Kentucky) for growing N. obtusifolia plants, preparing leaf washes and butyl esters, and to Victor D. Korenkov and Ivan Artiouchie for the technical support. We thank Dr. Sally Norton from Australian Grains Genebank for supplying seeds of $N$. occidentalis and N. occidentalis var. Hesperis. We thank Dr. Socrates Canete (KTRDC, University of Kentucky) for the helpful discussion regarding GC-MS detection sensitivity.

\section{Appendix A. Supplementary data}

Supplementary Fig. S1. 


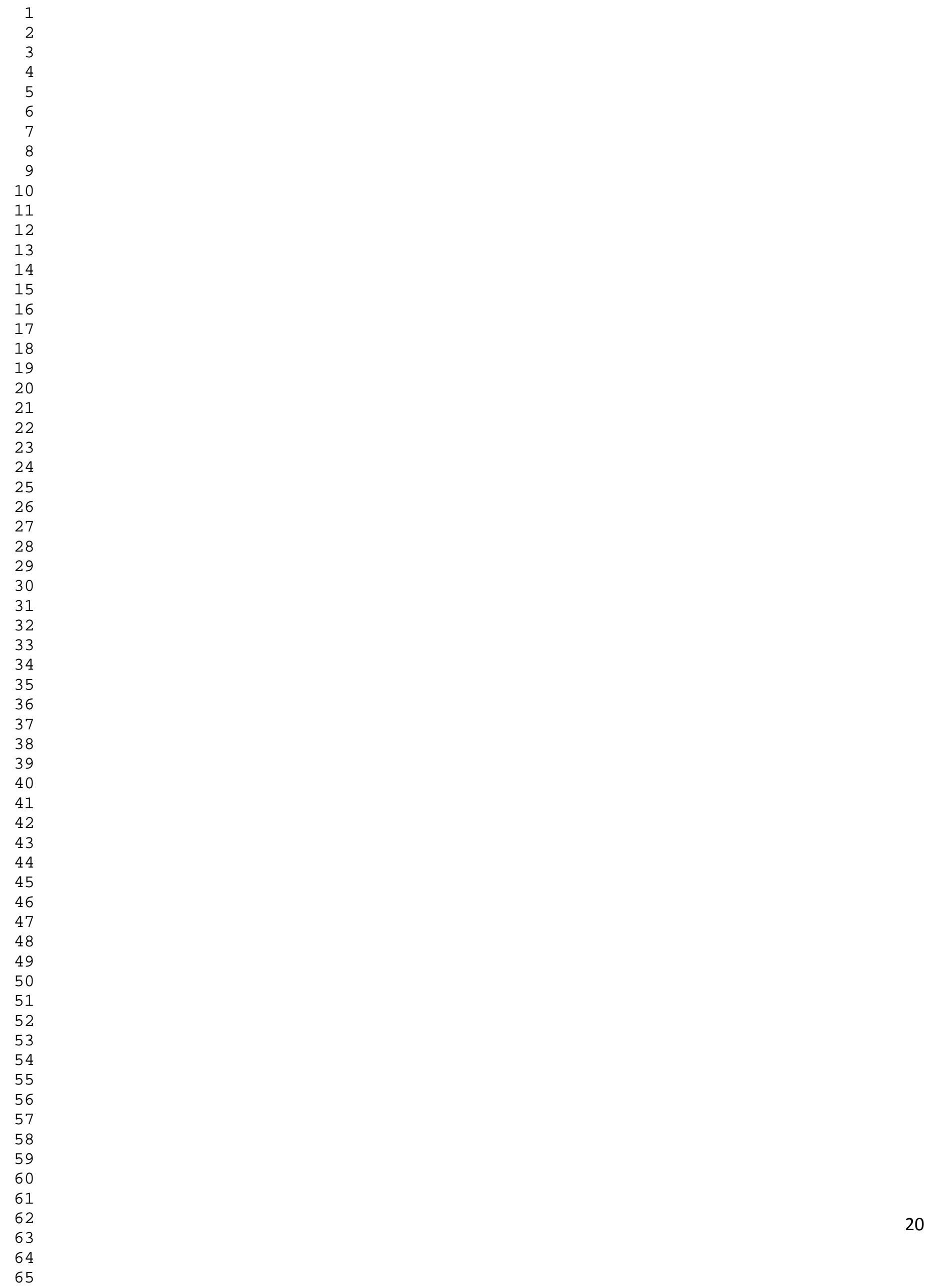




\section{Figure captions:}

Figure 1. Structure of all acyl groups detected.

A designated number and an abbreviation for each group are given in parenthesis. 
Fig. 1

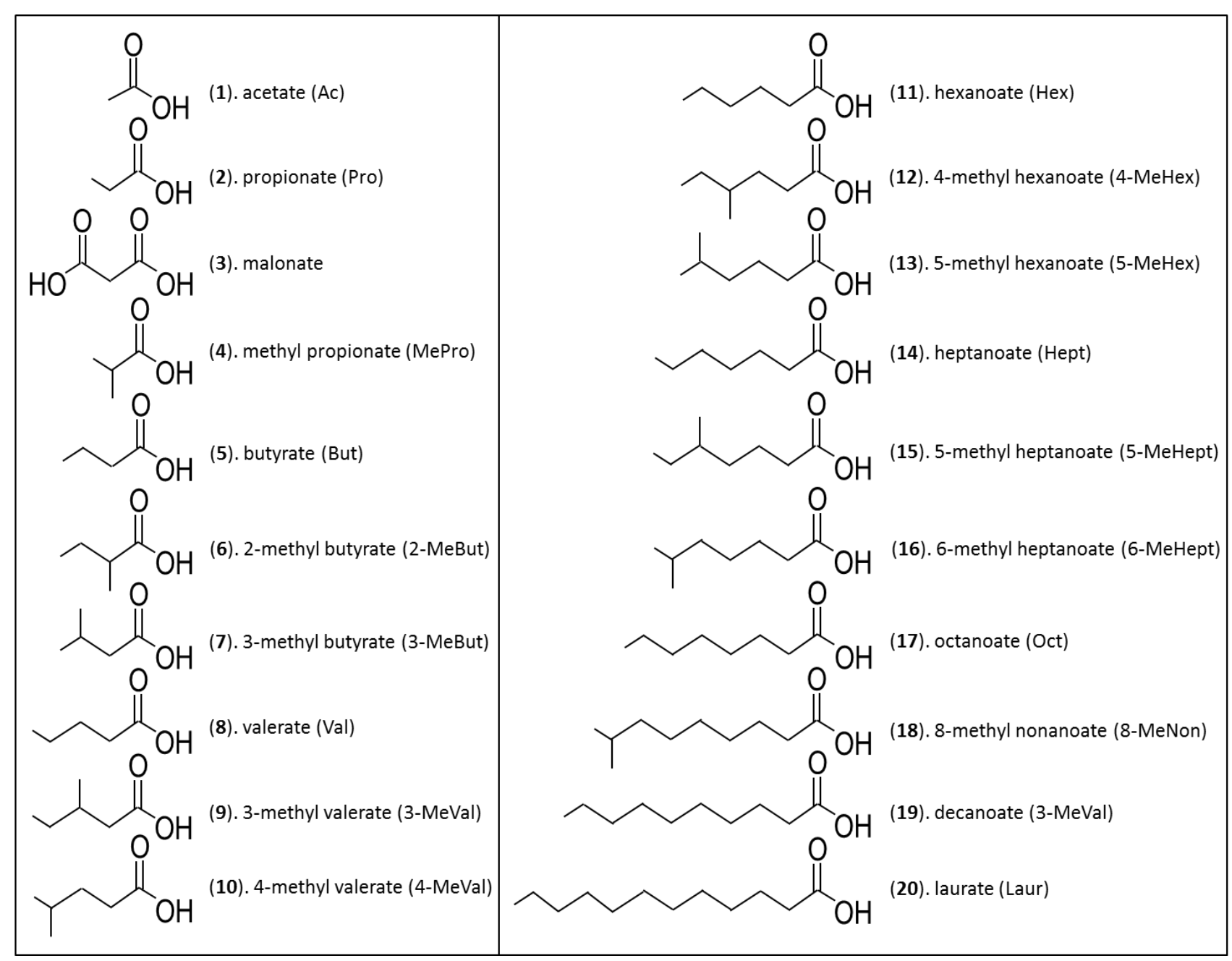


Table 1. Relative abundance of acyl groups in the accessions of Nicotiana obtusifolia.

\begin{tabular}{|c|c|c|c|c|c|c|c|c|c|c|c|}
\hline Acyl group & $\begin{array}{l}\text { DZO2- } \\
012\end{array}$ & $\begin{array}{l}\text { DZO2- } \\
013\end{array}$ & $\begin{array}{l}\text { DZ0 } \\
2- \\
014\end{array}$ & $\begin{array}{l}\text { DZO2- } \\
015\end{array}$ & $\begin{array}{c}\text { DZO2- } \\
016\end{array}$ & $\begin{array}{l}\text { DZO2- } \\
017\end{array}$ & $\begin{array}{l}\text { DZ02 } \\
-018\end{array}$ & $\begin{array}{l}\text { DZO2 } \\
-019\end{array}$ & $\begin{array}{l}\text { DZ02- } \\
20\end{array}$ & $\begin{array}{l}\text { DZ02- } \\
21\end{array}$ & $\begin{array}{l}\text { DZO2- } \\
22\end{array}$ \\
\hline \multicolumn{12}{|c|}{$\begin{array}{l}\text { mol \% of } \\
\text { highest }\end{array}$} \\
\hline $\operatorname{Ac}(\mathbf{1})$ & 75.5 & 68.8 & 72.0 & 19.1 & 94.5 & 45.5 & $\underline{100}$ & 4.7 & 87.4 & 100 & $\underline{100}$ \\
\hline MePro(4) & 24.3 & 27.4 & 21.5 & 10.3 & 37.1 & 29.1 & 22.3 & 7.0 & 24.7 & 27.2 & 38.0 \\
\hline But(5) & 8.4 & 9.2 & 14.6 & 3.3 & 6.1 & 7.0 & 11.6 & - & 7.0 & 7.5 & 9.6 \\
\hline 2-MeBut(6) & 77.1 & 69.1 & 56.7 & 63.8 & 78.5 & $\underline{100.0}$ & 86.1 & 42.8 & $\underline{100}$ & 93.2 & 66.8 .0 \\
\hline 3-MeBut(7) & 7.0 & 7.7 & 6.4 & 4.4 & 9.1 & 14.0 & 11.2 & 4.8 & 5.4 & 10.9 & 12.9 \\
\hline 3-MeVal(9) & 10.3 & 13.0 & 15.4 & 5.1 & 9.9 & 9.7 & 14.1 & 10.0 & 5.9 & 8.7 & 16.6 \\
\hline 4-MeVal(10) & 9.6 & 9.7 & 8.7 & 10.2 & 9.0 & 8.9 & 9.0 & 13.7 & 6.7 & 9.8 & 6.6 \\
\hline $\operatorname{Hex}(\mathbf{1 1})$ & 2.4 & $-{ }^{b}$ & - & - & - & - & - & - & - & - & - \\
\hline 4-MeHex(12) & 70.7 & 56.8 & 90.7 & 61.5 & 47.6 & 54.2 & 73.6 & 48.7 & 45.2 & 53.2 & 36.3 \\
\hline 5-MeHex(13) & $\underline{100}^{\mathrm{a}}$ & $\underline{100}$ & 86.9 & $\underline{100}$ & $\underline{100}$ & 89.5 & 81.0 & 78.0 & 55.8 & 92.4 & 69.4 \\
\hline 5-MeHept(15) & 60.8 & 71.6 & $\underline{100}$ & 14.7 & 55.8 & 50.7 & 66.7 & $\underline{100}$ & 12.5 & 45.1 & 82.3 \\
\hline 6-MeHept(16) & 7.2 & 12.3 & 8.2 & $\operatorname{tr}^{\mathrm{c}}$ & 7.7 & 6.2 & 7.3 & 11.6 & 2.2 & 5.4 & 14.5 \\
\hline \multirow[t]{2}{*}{ Acyl group } & $\begin{array}{c}\text { BBNP } \\
-8\end{array}$ & $\begin{array}{c}\text { BBNP } \\
-9\end{array}$ & $\begin{array}{l}\text { BBN } \\
\text { P-10 }\end{array}$ & $\begin{array}{c}\text { BBNP } \\
-11\end{array}$ & $\begin{array}{c}\text { BBNP- } \\
12\end{array}$ & $\begin{array}{l}\mathrm{ZHO4-} \\
8\end{array}$ & $\begin{array}{c}\text { ZSO5- } \\
04\end{array}$ & $\begin{array}{l}\text { ZS05- } \\
05\end{array}$ & $\begin{array}{c}55557 \\
3\end{array}$ & $\begin{array}{c}55554 \\
3\end{array}$ & \\
\hline & \multicolumn{11}{|c|}{$\begin{array}{c}\text { mol \% of } \\
\text { highest }\end{array}$} \\
\hline $\operatorname{Ac}(\mathbf{1})$ & 66.07 & 66.1 & 79.3 & 64.5 & 71.1 & 75.3 & 93.5 & 86.1 & 51.5 & 37.5 & \\
\hline MePro(4) & 24.3 & 17.7 & 18.3 & 16.4 & 18.0 & 18.3 & 15.9 & 22.3 & 12.0 & 27.9 & \\
\hline But(5) & 16.2 & 9.6 & 7.6 & 11.5 & 5.5 & 13.1 & 5.9 & 5.2 & 4.2 & 3.8 & \\
\hline 2-MeBut(6) & 85.5 & 83.0 & 98.1 & 64.5 & 86.8 & 57.8 & $\underline{100}$ & $\underline{100}$ & 41.9 & $\underline{100}$ & \\
\hline 3-MeBut(7) & 7.7 & 3.7 & 8.8 & 7.3 & 6.8 & 8.7 & 4.9 & 8.8 & 3.8 & 11.1 & \\
\hline 3-MeVal(9) & 24.7 & 13.2 & 17.4 & 25.8 & 16.1 & 36.6 & 2.6 & 4.0 & 18.9 & 6.5 & \\
\hline 4-MeVal(10) & 9.7 & 8.4 & 10.4 & 8.3 & 10.7 & 7.0 & 6.3 & 6.1 & 5.4 & 6.6 & \\
\hline $\operatorname{Hex}(\mathbf{1 1})$ & - & 2.4 & 2.6 & - & 1.9 & - & - & - & 0.7 & - & \\
\hline 4-MeHex(12) & $\underline{100}$ & $\underline{100}$ & $\underline{100}$ & $\underline{100}$ & $\underline{100}$ & 75.3 & 20.3 & 25.5 & $\underline{100}$ & 26.1 & \\
\hline 5-MeHex(13) & 63.06 & 78.3 & 84.1 & 49.1 & 80.9 & 27.0 & 63.6 & 56.9 & 28.8 & 51.5 & \\
\hline 5-MeHept(15) & 73.6 & 54.7 & 60.2 & 71.7 & 55.0 & $\underline{100}$ & 0.5 & 3.9 & 47.2 & 23.9 & \\
\hline 6-MeHept(16) & $\operatorname{tr}$ & 4.6 & 4.1 & 4.06 & 3.1 & 4.4 & - & - & 1.3 & 2.9 & \\
\hline
\end{tabular}

${ }^{a}$ major acid is underlined; ${ }^{b}$ not found; *white rows-straight chain; light-grey rows - iso chains; dark-grey - anteiso chains 
Table 2. Relative abundance of acyl groups in tobacco cultivars, ornamental varieties, and wild tobaccos.

\begin{tabular}{|c|c|c|c|c|c|c|c|c|c|c|}
\hline Acyl group & TI 1068 & KY14 & $\begin{array}{c}\text { TI } \\
165\end{array}$ & KDH 960 & N. sv/vestris & $\begin{array}{l}\text { N. alata } \\
\text { PI } 555474\end{array}$ & $\begin{array}{l}\text { N. alata } \\
\text { PI } 42334\end{array}$ & N. alata & x sanderae & N. noctiflora \\
\hline \multicolumn{11}{|c|}{ mol \% of highest } \\
\hline$A c(1)^{*}$ & 78.7 & $\underline{100}$ & 69.7 & $\underline{100}$ & $\underline{100}$ & $\underline{100}$ & $\underline{100}$ & 89.7 & 61.9 & 35.0 \\
\hline Pro(2) & 1.8 & 2.3 & 9.2 & $\operatorname{tr}^{a}$ & - & $\operatorname{tr}$ & 11.7 & 12.8 & 1.6 & $\operatorname{tr}$ \\
\hline MePro(4) & 13.3 & 10.9 & 19.9 & 31.9 & - & 83.9 & 30.5 & 34.0 & 11.0 & 5.4 \\
\hline But(5) & 3.7 & 3.1 & 17.8 & 18.5 & 10.3 & 37.2 & 24.8 & 27.2 & 10.5 & 1.6 \\
\hline 2-MeBut(6) & 28.8 & 59.7 & 28.4 & 38.7 & 7.4 & 58.8 & 88.4 & $\underline{100}$ & 87.0 & 2.4 \\
\hline 3-MeBut(7) & 29.1 & 44.2 & 35.0 & 65.5 & 1.6 & 36.3 & 30.5 & 17.2 & 2.5 & 64.6 \\
\hline 3-MeVal(9) & $\underline{100}^{\mathrm{a}}$ & $\operatorname{tr}$ & $\underline{100}$ & - & 2.9 & $\operatorname{tr}$ & 22.3 & 24.8 & 5.5 & 16.0 \\
\hline 4-MeVal(10) & 5.4 & & 11.8 & - & 1.5 & $\operatorname{tr}$ & $\operatorname{tr}$ & $\operatorname{tr}$ & - & 4.8 \\
\hline $\operatorname{Hex}(\mathbf{1 1})$ & $-b$ & - & - & - & - & 43.6 & 15.5 & 16.1 & 10.0 & \\
\hline 4-MeHex(12) & $\operatorname{tr}^{c}$ & 5.2 & - & - & 24.2 & - & - & - & - & 2.2 \\
\hline 5-MeHex(13) & - & $\operatorname{tr}$ & 9.6 & - & 7.7 & - & - & - & - & $\underline{100}$ \\
\hline 5-MeHept(15) & - & - & - & - & - & - & - & - & - & 13.6 \\
\hline 6-MeHept(16) & - & - & - & - & - & - & - & - & - & 9.7 \\
\hline Oct(17) & - & 5.6 & - & - & - & 87.4 & 57.0 & 59.4 & $\underline{100}$ & - \\
\hline
\end{tabular}

${ }^{\mathrm{a}}$ traces; ${ }^{\mathrm{b}}$ not found; ${ }^{*}$ white rows - straight chain; light grey rows - iso chains; dark grey rows - anteiso chains 
Table 3. Relative abundance of acyl groups in Nicotiana species from Australia.

\begin{tabular}{|c|c|c|c|c|c|c|c|c|c|c|c|c|c|}
\hline \multirow[b]{2}{*}{ Acyl group } & \multicolumn{10}{|c|}{$\begin{array}{l}\text { Nicotiana occidentalis subsp. } \\
\underline{\text { hesperis }}\end{array}$} & \multicolumn{3}{|c|}{$\begin{array}{l}\text { Nicotiana } \\
\underline{\text { occidentalis }}\end{array}$} \\
\hline & $\begin{array}{r}303663 \\
\text { leaves } \\
\end{array}$ & $\begin{array}{l}303767 \\
\text { leaves }\end{array}$ & $\begin{array}{c}303765, \\
\text { leaves }\end{array}$ & $\begin{array}{c}303765 \\
\text { stem }\end{array}$ & $\begin{array}{l}303721, \\
\text { leaves }\end{array}$ & $\begin{array}{c}303721 \\
\text { stems+sepals }\end{array}$ & \multicolumn{2}{|c|}{$\begin{array}{c}\text { 303763, 303763, } \\
\text { leaves stems }\end{array}$} & $\begin{array}{c}\text { 303764, } \\
\text { leaves+stems }\end{array}$ & $\begin{array}{c}555541 \\
\text { leaves+stems }\end{array}$ & \multicolumn{3}{|c|}{$\begin{array}{l}555689555689555689 \\
\text { leaves stems sepals }\end{array}$} \\
\hline & & & & $\mathrm{mol} \% \mathrm{c}$ & f highes & & & & & & $\mathrm{mol} \% \mathrm{c}$ & of highes & \\
\hline $\operatorname{Ac}(\mathbf{1})^{*}$ & 52.6 & 52.5 & $\underline{100}$ & $\underline{100}$ & 86.9 & 91.6 & 55.6 & $\underline{100}$ & $\underline{100}$ & 80.5 & $\underline{100}$ & $\underline{100}$ & $\underline{100}$ \\
\hline Pro(2) & $-{ }^{b}$ & 4.3 & 7.1 & 1.5 & - & 0.3 & 22.1 & 0.3 & 0.52 & 0.64 & 9.6 & 18.3 & 3.7 \\
\hline MePro(4) & 26.4 & 11.1 & 80.4 & 55.8 & 65.5 & 22.0 & $\underline{100}$ & 55.7 & 10.4 & 16.3 & 25.6 & 43.4 & 33.5 \\
\hline But(5) & 8.1 & 2.9 & 11.8 & 0.8 & - & 1.7 & 28.7 & 1.9 & 0.9 & 1.1 & 13.4 & 27.8 & 5.2 \\
\hline 2-MeBut(6) & 25.5 & 32.1 & 30.1 & 7.5 & 51.6 & 61.3 & 22.0 & 8.6 & 67.1 & $\underline{100}$ & 21.5 & 15.0 & 18.7 \\
\hline 3-MeBut(7) & 15.2 & 8.2 & 39.0 & 15.5 & 45.6 & 20.7 & 23.2 & 18.5 & 14.8 & 7.2 & 30.8 & 8.7 & 5.2 \\
\hline $\operatorname{Val}(8)$ & - & - & & - & - & 2.1 & - & 0.5 & 1.1 & 0.7 & 9.0 & - & - \\
\hline 3-MeVal(9) & $\underline{100}^{\mathrm{a}}$ & $\underline{100}$ & 23.0 & 6.4 & $\underline{100}$ & $\underline{100}$ & 7.9 & 8.0 & 86.9 & 62.6 & 66.3 & 16.5 & 0.0 \\
\hline 4-MeVal(10) & 10.5 & 5.3 & 73.8 & 61.6 & 34.5 & 16.9 & 53.2 & 74.8 & 6.6 & 0.9 & 7.8 & - & 5.4 \\
\hline $\operatorname{Hex}(\mathbf{1 1})$ & - & - & 10.8 & 0.6 & & 2.8 & & 1.1 & & - & - & - & - \\
\hline 4-MeHex(12) & $\operatorname{tr}^{c}$ & 1.2 & 14.8 & 4.7 & $\operatorname{tr}$ & 4.1 & 5.0 & 5.8 & 2.5 & - & & 17.9 & 9.2 \\
\hline 5-MeHex(13) & $\operatorname{tr}$ & $\operatorname{tr}$ & 54.7 & 30.2 & 77.1 & 2.8 & 18.5 & 33.6 & $\operatorname{tr}$ & - & 10.2 & 27.2 & 75.8 \\
\hline Hept(14) & - & - & 11.1 & 0.4 & - & 1.9 & - & 1.0 & - & - & - & - & - \\
\hline 5-MeHept(15) & - & - & - & - & - & - & - & - & - & - & 19.8 & 65.1 & 65.3 \\
\hline 6-MeHept(16) & - & - & - & - & - & - & - & - & - & - & - & 11.0 & 9.1 \\
\hline 8-MeNon(18) & 9.7 & - & 20.6 & $\operatorname{tr}$ & - & - & 34.6 & - & 2.0 & - & - & - & - \\
\hline $\operatorname{Dec}(\mathbf{1 9})$ & $\operatorname{tr}$ & - & 17.3 & 0.3 & - & 0.4 & 13.7 & 0.5 & 1.6 & - & - & - & - \\
\hline
\end{tabular}

\footnotetext{
${ }^{a}$ traces, ${ }^{b}$ not found; ${ }^{*}$ white rows - straight chain; light grey rows - iso chains; dark grey - anteiso chains
} 
Table 4. Relative abundance of acyl groups in Petunia, S. bertaultii, and S. Pennellii.

\begin{tabular}{|c|c|c|c|c|c|c|c|c|c|}
\hline Acyl group & $\begin{array}{l}\text { P.Madness } \\
\text { Red Picotee }\end{array}$ & $\begin{array}{l}\text { P. Dreams } \\
\text { Red Picotee }\end{array}$ & $\begin{array}{l}\text { P. Silver } \\
\text { Tidal Wave }\end{array}$ & $\begin{array}{l}\text { P.Purple } \\
\text { Tidal Wave }\end{array}$ & $\begin{array}{c}\text { Petunia Pink } \\
\text { Tidal Wave }\end{array}$ & $\begin{array}{c}\text { Kays et } \\
\text { al.,1994 }\end{array}$ & S.berthaultii & $\begin{array}{l}\text { Neal et } \\
\text { al.,1990 }\end{array}$ & S.pennelliit \\
\hline \multicolumn{10}{|c|}{ mol \% of highest } \\
\hline $\mathrm{Ac}(\mathbf{1})^{*}$ & 48.7 & 39.5 & 19.0 & 33.3 & $\underline{28.4}$ & 38.0 & $\operatorname{tr}$ & - & 1.9 \\
\hline Pro(2) & 7.7 & 2.7 & 3.3 & 8.9 & 9.3 & - & 4.3 & 1.2 & 0.8 \\
\hline Malonate(3) & $\underline{100^{a}}$ & 98.5 & 82.7 & $\underline{100}$ & $\underline{100}$ & - & - & - & - \\
\hline MePro(4) & 14.4 & 7.3 & 2.8 & 17.15 & 18.1 & - & $\underline{100}$ & $\underline{100}$ & $\underline{100}$ \\
\hline But(5) & 18.0 & 6.5 & 6.5 & 10.7 & 12.7 & 4.0 & 4.3 & 2.3 & 1.0 \\
\hline 2-MeBut(6) & 77.2 & $\underline{100}$ & 44.3 & 92.1 & 31.2 & $\underline{100}$ & 76.5 & 62.2 & 43.4 \\
\hline 3-MeBut(7) & 15.0 & 18.3 & 5.4 & 14.2 & 21.8 & 12 & 24.8 & - & 12.3 \\
\hline $\operatorname{Val}(8)$ & 18.2 & 7.6 & 14.9 & 7.8 & 9.2 & 7.0 & - & - & - \\
\hline 3-MeVal(9) & 12.9 & 5.2 & 3.2 & 5.1 & 83.4 & - & - & - & 5.1 \\
\hline 4-MeVal(10) & 14.9 & 35.4 & 7.6 & 2.1 & 27.3 & 32 & - & - & $\operatorname{tr}^{c}$ \\
\hline $\operatorname{Hex}(\mathbf{1 1})$ & 61.7 & 36.2 & $\underline{100}$ & 6.0 & 23.9 & 37.0 & - & - & - \\
\hline 4-MeHex(12) & $-{ }^{b}$ & - & - & 3.1 & 27.0 & 5 & - & - & - \\
\hline $5 \mathrm{MeHex}(\mathbf{1 3})$ & - & - & 2.3 & 2.9 & - & 10 & - & - & - \\
\hline Hept(14) & 23.2 & 13.5 & 35.9 & 15.3 & 15.7 & 21.0 & - & - & - \\
\hline 6MeHept(16) & - & - & - & - & - & - & - & - & 0.9 \\
\hline Oct(17) & 8.7 & 3.8 & 4.4 & 32.4 & 5.7 & 5.0 & 3.5 & - & - \\
\hline 8-MeNon(18) & - & - & - & - & - & - & - & 47.9 & 58.9 \\
\hline $\operatorname{Dec}(\mathbf{1 9})$ & - & - & - & - & - & - & 80.6 & 4.4 & 17.6 \\
\hline Laur(20) & - & - & - & - & - & - & - & 4.4 & 6.2 \\
\hline
\end{tabular}

${ }^{a}$ major acid is underlined; ${ }^{b}$ traces; ${ }^{c}$ not found; * white rows-straight chain; ligh- grey rows - iso chains; dark-grey - anteiso chains; †Non and 9-MeDec were observed in trace amounts in S. pennellii. 


\section{References:}

Arrendale, R.F., Severson, R.F., Sisson, V.A., Costello, C.E., Leary, J.A., Himmelsbach, D.S., van Halbeek, H., 1990. Characterization of the sucrose fraction from Nicotiana glutinosa. J. Agric. Food Chem. 38, 75-85. Johnson, A.W., Severson, R.F., 1984. Leaf surface chemistry of tobacco budworm resistant tobacco. J. Agric. Enlomol. 1(1): 23-32.

Pérez-Castorenaa, A.L., Lunaa, M., Martínez, M., Maldonadoa, E., 2012. New sucrose esters from the fruits of Physalis solanaceus. Carbohydrate Research. 352, 211-214

Burk, B.A., Goldsby, G., Mudd, J.B., 1987. Polar epicuticular lipids of Lycopersicon pennellii. Phytochemistry $26,2567-2671$.

Chaplin, J.F., Stavely, J.R., Litton, C.C., Pitarelli, G.W., West Jr, W.H., 1982. Catalog of the tobacco introductions in the US Department of agriculture's tobacco germplasm collection (Nicotiana tabacum). USDA-ARD. ARM-S-27.

Chortyk, O.T., 1997. Characterization of insecticidal sugar esters of Petunia. J. Agric. Food Chem. 45, 270275.

Chortyk, O.T., Severson, R.F., Cutler, H.C., Sisson, V.A., 1993. Antibiotic activities of sugar esters isolated from selected Nicotiana species. Biosci. Biotechnol. Biochem. 57, 1355-1356

Cutler, H.G., Severson, R.F., Cole, R.D., Sisson, V.A., Jackson, M.D., Stephenson M.G., 1992. The biological activity of some mixed sucrose and glucose esters from exotic tobacco cultivars. PGRSA Quarterly 20, 18-

28.

Fobes, .JF., Mudd, J.B., Marsen, M.P.F., 1985. Epicuticular lipid accumulation on the leaves of Lycopersicon pennelli (Corr.) D’Arcy and Lycopersicon esculentum Mill. Plant Physiol. 77, 567-570.

Glas, J.J., Schimmel, B.C.J., Alba, J. M.,.Escobar-Bravo, R., Schuurink, R., Kant, M.R., 2012. Plant glandular trichomes as targets for breeding or engineering of resistance to herbivores. Int. J. Mol. Sci. 13, 1707717103; doi: 10.3390/ijms131217077 
Ghosh, B., Westbrook, T.C., Jones, A.D., 2014. Comparative structural profiling of trichome specialized metabolites in tomato (Solanum lycopersicum) and S. habrochaites: acylsugar profiles revealed by UHPLC/MS and NMR. Metabolomics 10, 496-507., doi 10.1007/s11306-013-0585-y Heist, E.P., Zaitlin, D., Funnell, D.L., Nesmith, W.C., Schardl, C.L., 2004. Necrotic lesion resistance induced by Peronospora tabacina on leaves of Nicotiana obtusifolia. Phytopathology 94, 1178-1188.

Hill, K., Rhode, O., 1999. Sugar-based surfactants for consumer products and technical application. Fett/Lipid. 101, 25-33.

Holley, J.D., King, R.R., Singh, R.P., 1987. Glandular trichomes and the resistance of Solanum berthaultii (PI 473340) to infection from Phytophthora infestans. Can. J. Plant Pathol. 9, 291-294.

Jia, C., Wang, W., Zhu, Y., Xu, C., Mao, D., 2013. Preparative isolation and structural characterization of sucrose ester isomers from oriental tobacco. Carbohydr. Res. 372, 73-77

Johnson, J.C., Nielsen, M.T.G., Collins, B., 1988. Inheritance of glandular trichomes in tobacco. Crop Sci. 28, 241-244.

Jackson, D., Chortyk, O., Stephenson, M., Johnson, A., Harlow, C., Simmons, A., Sisson, V., 1998. Potential of Nicotiana species for production of sugar esters. Tob. Sci. 42.

Kaburaki, W., Mikami, Y., Nakamura, M., 1969. Studies on the composition of tobacco smoke. XIII. Volatile acids in tobacco smoke. SCl. Papers Rentral Res. Inst., Japan Monopoly Corp. 111, 159-168.

Kallianos, A.G., 1976. Phenolics and acids in leaf and their relationship to smoking quality and aroma. Rec. Adv. Tob. Sci. 2, 61-79.

Kays, S.J., Severson, R.F., Nottingham, S.F., Chalfant, R.B., Chortyk, O., 1994. Possible biopesticide from petunia for the control of sweetpotato whitefly (Bemisia tabaci) on vegetable crops. Proc. Fla. State Hort. Soc. $107,163-167$. 
Kelsey, R., Reynolds, G., Rodrigues, E., 1984. The chemistry of biologically active constituents secreted and stored in plant glandular trichomes, In: Rodriguez, E., Healey, P.L., Mehta, I. (Eds.), Biology and chemistry of plant trichomes. Plenum Press, New York, etc. pp.187-241.

Kim, J., Kang, K., Gonzales-Vigil, E., Shi F, Jones, A.D., Barry, C.S., Last, R.L., 2012. Striking natural diversity in glandular trichome acyl sugar composition is shaped by variation at the acyltransferase2 locus in the wild tomato Solanum habrochaites. Plant Physiol. 160, 1854-1870.

King, R.R., Pelletier, Y., Singh, R.P., Calhoun, L.A., 1986. 3,4-Di-O-isobutyryl-6-O-caprylsucrose: The major component of a novel sucrose ester complex from the type B glandular trichomes of Solanum berthaultii Hawkes (PI 473340) J. Chem. Soc. 14, $1078-10$.

Kroumova, A.B., Xie Z., Wagner, G.J., 1994. A pathway for the biosynthesis of straight ad branched, odd-and even-length, medium-chain fatty acids in plants. Proc. Natl. Acad. Sci. 91, 11437-11441.

Kroumova, A.B., Wagner, G.J., 1995. Methods for separation of free, short, medium, and long chain fatty acids and for their decarboxylation. Anal. Biochem. 225, 270-276.

Kroumova, A.B., Wagner, G.J., 2003. Different elongation pathways in the biosynthesis of acyl groups of trichome exudate sugar esters from various solanaceous plants. Planta. 216, 1013-21.

Leffingwell, J.C., 1999. Basic chemical constituents of tobacco leaf and differences among tobacco types In:

Davis, D.L., Nielsen, M.T. (Eds.), Tobacco production, chemistry and technology, CORESTA, Blackwell Science Ltd, pp. 265-284.

Leitch, I.J., Hanson, L., Lim, K.Y., Kovarik, A., Chase, M.W., Clarkson, J.J., Leitch, A.R., 2008. The ups and downs of genome size evolution in polyploid species of Nicotiana (Solanaceae). Ann. Bot. 101, 805-814. Matsuzaki, T., Shinozaki, Y.S., Suhara, S., Ninomiya, M., Shigematsu, H., Koiwai, A., 1989. Isolation of glycolipids from the surface lipids of Nicotiana bigelovii and their distribution in Nicotiana species. Agric. Biol. Chem. 53, 3079-3082. 
Matsuzaki, T., Shinozaki, Y.S., Hagimori, M., Tobita, T., Shigematsu, H., Koiwai, A., 1992. Novel glycolipids from the surface lipids of Nicotiana benthamiana. Biosci. Biotech. Biochem. 56, 1565-1569.

Murashige, T., Skoog, F., 1962. A revised medium for rapid growth and bioassay with tobacco tissue culture. Physiol. Plant. 15, 73-97.

Nielsen., M.T., Jones, G.A,. Collins, G.B., 1982. Inheritance pattern for secreting and nonsecreting glandular trichomes in tobacco. Crop Sci. 22, 1051-1053.

Nielsen, M.T., 1989. Registration of KDH926, KDH 959, KDH 960 tobacco germplasm lines with different levels of trichome exudate constituents. Crop Sci. 29, 1584

Neal, J.J., Tingey, W.M., Steffens, J., 1990. Sucrose esters of carboxylic acids in glandular trichomes of Solanum berthaultii deter settling and probing by green peach aphid. J. Chem. Ecol. 16, 487-497

Ohya, I., Sinozaki, Y., Tobita, T., Takahashi, H., Matsuzaki, T., Koiwai, A. 1994. Sucrose esters from the surface lipids of Nicotiana cavicola. Phytochem. 37, 143-5.

Perez, L.A., De Vivar, A.R., 1989. Triacyl glucopyranoses from Bahia schaffneri. Phytochemistry. 28, 16391643.

Peterson, J.K., Snook, M.E., Harrison Jr., H.F., Mason, P., 1998. Isolation and structural identification of sucrose esters from corn spurrey (Spergula arvensis); Inhibition of seed germination. J. Chem. Ecology. 24, $1573-1561$.

Puterka, G.J., Farone, W., Palmer, T., Barrington, A., 2003. Structure-function relationships affecting the insecticidal and miticidal activity of sugar esters. J. Econ. Entomol. 96, 636-644.

Roberts, K.L., Thurston, R., Jones, G.A., 1981. Density of types of trichomes on leaf lamina of various tobacco cultivars. Tob. Sci. 25:68-69.

Salanitro, J.P., Muirhead, P.A., 1975. Quantitative method for the gas chromatographic analysis of shortchain monocarboxylic and dicarboxylic acids in fermentation media. Appl Microbiol. 3, 374-381. 
Severson, R.F., Arrendale, R.F., Chortyk, O.T., Green, C.R., Thome, F.A., Stewart, J.L., Johnson, A.W., 1985 a. Isolation and characterization of the sucrose esters of the cuticular waxes of green tobacco leaf. J. Agric. Food Chem. 33, 870-875.

Severson, R.F., Johnson, A.W., Jackson, D.M., 1985b. Molecular constituents of tobacco: Factor affecting their production and their role in insect and disease resistance and smoke quality, Recent Adv. Tob. Sci. 11, 105-174.

Severson, R.F., Jackson, D.M., Johnson, A.W. Sisson, W.A., Stephenson, M.G., 1991. Ovipositional behavior of tobacco budworm and tobacco hornworm: Effects of curricular components from Nicotiana species. In: Hedin, P.A. (Ed.), Naturally occurring pest bioregulators. ACS, Washington DC 1991. pp.264-277. Shepherd, R.W., Wagner, J.G., 2012. Fungi and leaf surfaces, in: Southworth, D. (Ed.), Biocomplexity of plant-fungal interactions. Wiley-Blackwell, John Wiley and Sons, Inc., pp. 131-154.

Schilmiller, A.L., Moghe, G.D., Fan, P., Ghosh, B., Ning, J., Jones, A.D., Last, R.L., 2015. Functionally divergent alleles and duplicated loci encoding an acyltransferase contribute to acylsugar metabolite diversity in Solanum trichomes. The Plant Cell, 27, 1002-1017.

Slocombe, S.P., Schauvinhold, I., McQuinn, R.P., Besser, K., Welsby, N.A., Harper, A., Aziz, N., Li. Y., Larson, T.R., Giovannoni, J., Dixon, R.A., Broun, P., 2008. Transcriptomic and reverse genetic analyses of branchedchain fatty acid and acyl sugar production in Solanum pennellii and Nicotiana benthamiana. Plant Physiol. $148,1830-1846$.

Son, K.C., Severson, R.F., Pair, S.D., Kays, S.J,. 1994. Comparison of the component fatty acid of cuticular sucrose esters from flowers and buds of three Petunia x hybrid Hort. Cultivars. Han'guk Wonye Hakhoechi $35,617-622$

Tangreman, A., Nagengast, F.M., 1996. A gas chromatographic analysis of fecal short-chain fatty acids using the direct injection method. Anal Biochem, 236, 1-8.

Tissier, A., 2012. Glandular trichomes: what comes after expressed sequence tags? The Plant J. 70, 51-68. 
van Eijk, H. M.H., Bloemen, J. G., Dejong, C. H.C., 2009. Application of liquid chromatography-mass spectrometry to measure short chain fatty acids in blood. J. Chromat. B, 877, 719-724.

Wagner, G.J., 1991. Secreting glandular trichomes: More than just hairs. Plant Physiol. 96, 675-679.

Wagner, G. J. 1999. Leaf surface chemistry. in: Davis, D.L. Nielsen, M.T. (Eds.), Tobacco: Production, Chemistry, and Technology; Blackwell Science: Cambridge; pp. 292-303.

Wagner, G.J., Wang, E., Shepherd, R.W., 2004. New approaches for studying and exploiting an old protuberance, the plant trichome. Annals of Botany 93, 3-11. doi:10.1093/aob/mch011, available online at $\underline{\text { www.aob.oupjournals.org }}$

Walters, D.S., Steffens, J.C., 1990. Branched-chain amino acid metabolism in the biosynthesis of Lycopersicon pennellii glucose esters. Plant Physiol. 93, 1544-1551.

Zhao, G., Nyman, M., Jönsson, J.A., 2006. Rapid determination of short-chain fatty acids in colonic contents and faeces of humans and rats by acidified water-extraction and direct-injection gas chromatography.

Biomed. Chromatogr. 20, 674-682. DOI: 10.1002/bmc.580

Winkel-Shirley, B., 2001. Flavonoid biosynthesis: a colorful model for genetics, biochemistry, cell biology, and biotechnology. Plant Physiol. 126, 485-493. Doi: http//dx.doi.org/10.1104/pp.126.2.485 